\title{
Contributions to the History of Medical Informatics
}

Izet Masic and al. Avicena, Sarajevo, 2014. 264 pages; ISBN 978-9958-720-56-7

Health professionals are able to make right decision in right time only if they posses prompt, accurate and up to date information about health status of patients and general population. They also need knowledge and tools, computer and information technologies, for successful management of huge amount of information. Efficient management of information is of crucial importance for health policy and decision-making process, and to produce high quality results in public health and healthcare delivery.

The book presents an original effort to summarize the basic knowledge about the history of medical informatics and informatics education in Europe and broader, development stages and influence of computer sciences on development of medical informatics. In addition, history and development of medical informatics in Croatia and in Bosnia and Herzegovina is also presented, as well as some basic facts about the establishment, importance and activities of the two key international associations-IMIA and EFMI. A broad list of 36 key actors, with brief biographies and photos, is included, as the most influential scientists and doyens in development of medical informatics worldwide. The authors of the book pay special tribute to four corypheés of medical informatics-Morris F. Collen, François Grémy, Peter L. Reichertz and Jean-Claude Healy.
The book is fulfilling an important gap revealing the history and emphasizing the importance of medical informatics as a new scientific discipline with very fast development and implementation in health care sector. Health informatics is contributing remarkably in everyday practice of medical and public health professionals, in efficient management of huge and increasing amount of health information and general and specific medical knowledge toward improved quality of health care, as well as to professional and scientific competitiveness in Europe and broader. The knowledge of information technology is now part of general literacy.

The 264 pages are distributed in 14 chapters with references and consulted literature added to each chapter.

The book is directed toward medical and other professionals in biomedicine, especially the young doctors. The book can be used by students at all levels, from undergraduate to postgraduate master and doctoral studies, and professionals in various clinical disciplines and public health. The book can also be useful as a guideline for all medical and other professionals in biomedicine in conducting everyday activities and promoting of their professional and research work.

Skopje, August 2014

Prof. Doncho Donev, $\mathrm{MD}, \mathrm{PhD}$ 